Herz 2020 · 45:299

https://doi.org/10.1007/s00059-018-4731-1

Received: 9 June 2018

Accepted: 17 June 2018

Published online: 12 July 2018

(c) Springer Medizin Verlag $\mathrm{GmbH}$, ein Teil von Springer Nature 2018

CrossMark

To the editor,

I read with great interest the study of H.-X. Chang et al. [1] published in the latest issue of Herz. In our recent studies $[2,3]$, we too examined the role of epicardial adipose tissue (EAT) in patients with subclinical atherosclerosis and also in patients with coronary artery disease. In their interesting study [1], Chang and colleagues investigated the role of EAT lipolysis and the effect of EAT removal on cardiac function after myocardial infarction.

EAT is a visceral adipose tissue surrounding the heart and coronary arteries. By secreting pro-inflammatory and anti-inflammatory cytokines and chemokines, it is thought to influence the development of coronary atherosclerosis [2-5]. In our recently published study [2], we found that EAT thickness has a positive correlation with slow coronary flow in patients who have normal coronary arteries. Therefore, it can help predict the presence of subclinical atherosclerosis in patients with stable angina pectoris. Because of its close proximity, epicardial fat can affect the heart and coronary arteries locally through its vasocrine and paracrine secretions [6]. In our other study [3], we showed that patients with coronary artery disease had greater EAT thickness with higher gamma-glutamyltransferase (GGT) activity. A higher GGT activity, which is associated with atherosclerosis, was found to be independently associated with EAT thickness.

In the present study [1], removal of EAT after myocardial infarction in rats was found to improve cardiac function compared with rats retaining EAT after myocardial infarction. The authors ex-

\author{
M. R. Ege \\ Cardiology Clinic, Koru Hospital, Ankara, Turkey
}

\title{
Epicardial adipose tissue: good or bad for cardiac function?
}

plained this phenomenon by the weakening of the inflammatory response. Contrary to the findings of Chang et al.[1], Bière and colleagues [7] showed that in patients with ST-elevation myocardial infarction (STEMI), higher EAT was paradoxically related to smaller infarct size and patients with higher EAT had better cardiac healing. In another study [8], a lower EAT volume was found to be associated with less myocardial salvage and larger infarct size in patients with a first STEMI episode. In several studies, EAT was found to have an adverse effect on the myocardium; however, by secreting anti-inflammatory cytokines and chemokines, it is thought to supply energy and may protect the myocardium [7-9]. In the study of Chang et al. [1], similar to our findings, an EAT paradox was not found. An increase in EAT thickness independently predicts adverse cardiac events, and chronic inflammation in epicardial fat can predispose patients to these events. In my opinion, the role of EAT in cardiac function needs further investigation.

\section{Corresponding address}

\section{R. Ege}

Cardiology Clinic, Koru Hospital

Ankara, Turkey

drmeltemege@yahoo.com.tr

Conflict of interest. M.R. Ege declares that she has no competing interests.

\section{References}

1. Chang H-X, Zhao X-J, Zhu Q-L et al (2018) Removal of epicardial adipose tissue after myocardial infarction improves cardiac function. Herz. https:// doi.org/10.1007/s00059-017-4555-4

2. Comert N, Yucel O, Ege MR et al (2012) Echocardiographic epicardial adipose tissue predicts subclinical atherosclerosis: epicardial adipose tissue and atherosclerosis. Angiology 63:586-590. https://doi.org/10.1177/0003319711432452

3. Ege MR, Guray U, Guray Y et al (2013) Serum Y-glutamyltransferase levels correlate with epicardial adipose tissue thickness in patients with coronary artery disease. Angiology 64:21-25. https://doi. org/10.1177/0003319711433197

4. Eroglu S, Sade LE, Yildirir A et al (2009) Epicardial adipose tissue thickness by echocardiography is a marker for the presence and severity of coronary artery disease. Nutr Metab Cardiovasc Dis 19:211-217. https://doi.org/10.1016/j.numecd. 2008.05.002

5. Ahn SG, Lim HS, Joe DY et al (2008) Relationship of epicardial adipose tissue by echocardiography to coronary artery disease. Heart 94:e7

6. Baker AR, Silva NF, Quinn DW et al (2006) Human epicardial adipose tissue expresses a pathogenic profile of adipocytokines in patients with cardiovascular disease. Cardiovasc Diabetol 5:1

7. BièreL, BehaghelV, MateusVetal (2017)Relation of quantity of subepicardial adipose tissue to infarct size in patients with ST-elevation myocardial infarction. Am J Cardiol 119:1972-1978

8. Gohbara M, Iwahashi N, Akiyama E et al (2016) Association between epicardial adipose tissue volume and myocardial salvage in patients with a first ST-segment elevation myocardial infarction: an epicardial adipose tissue paradox. J Cardiol 68:399-405. https://doi.org/10.1016/j.jjcc.2015. 10.018

9. lacobellis G, Bianco AC (2011) Epicardial adipose tissue: emerging physiological, pathophysiological and clinical features. Trends Endocrinol Metab 22:450-457. https://doi.org/10.1016/j.tem.2011. 07.003 